\title{
A Novel Inhaled Organic Nitrate That Affects Pulmonary Vascular Tone in a Piglet Model of Hypoxia-Induced Pulmonary Hypertension
}

\author{
MICHAEL D. BRANDLER, STEVEN C. POWELL, DAMIAN M. CRAIG, GEORGE QUICK, \\ TIMOTHY J. MCMAHON, RONALD N. GOLDBERG, AND JONATHAN S. STAMLER \\ Department of Pediatrics [M.D.B., R.N.G.], Department of Medicine [S.C.P., T.J.M., J.S.S.], \\ Cardiothoracic Surgery [D.M.C., G.Q.], Department of Biochemistry [J.S.S.], Neonatal-Perinatal \\ Research Institute [M.D.B., R.N.G.], and Howard Hughes Medical Institute [J.S.S.], Duke University \\ Medical Center, Durham, NC 27710
}

\begin{abstract}
Persistent pulmonary hypertension of the newborn is characterized by elevated pulmonary vascular resistance after birth leading to right-to-left shunting and systemic arterial hypoxemia. Inhaled nitric oxide (NO) is effective in reducing the need for extracorporeal membrane oxygenation, but it has potential toxicities, especially in an oxygen-rich environment. A number of other NO-based molecules have been given by inhalation, but their structure-function relationships have not been established. Recent studies have raised the idea that toxic and beneficial properties can be separated. We synthesized a novel organic nitrate [ethyl nitrate $\left(\mathrm{ENO}_{2}\right)$ ], tested it in vitro, and administered it to hypoxic piglets. $\mathrm{ENO}_{2}$ lowered pulmonary artery pressure and raised the $\mathrm{PO}_{2}$ in arterial blood but did not alter systemic vascular resistance or methemoglobin levels. In addition, we tested the effect of $\mathrm{ENO}_{2}$ in the presence of the thiol glutathione, both in vivo and in vitro, and found its action to be enhanced. Although $\mathrm{ENO}_{2}$ is less potent than inhaled NO on a doseequivalency basis, pretreatment of hypoxic animals with glutathione, which may be depleted in injured lungs, led to a markedly enhanced effect (largely mitigating the difference in potency).
\end{abstract}

\section{ABSTRACT}

These results suggest that $\mathrm{ENO}_{2}$ may hold promise as a safe alternative to NO, particularly in hypoxemic conditions characterized by thiol depletion. (Pediatr Res 58: 531-536, 2005)

CO, cardiac output
ENO, ethyl nitrite
$\mathbf{E N O}_{2}$, ethyl nitrate
$\mathrm{GSH}_{\text {, glutathione }}$
$\mathrm{FIO}_{2}$, fraction of inspired oxygen
$\mathbf{N M R}$, nuclear magnetic resonance
$\mathbf{N O}$, nitric oxide
$\mathbf{N O}$, oxides of nitrogen
Pao
PAP, arterial pulmonartial pressure of oxygen
PPHN, persistent pulmonary hypertension of the newborn
PVR, pulmonary vascular resistance
SNO, S-nitrosothiol
SVR, systemic vascular resistance

The disease entity persistent pulmonary hypertension of the newborn (PPHN) is characterized by elevated pulmonary vascular resistance (PVR) after birth leading to extrapulmonary right-to-left shunting through the patent foramen ovale and patent ductus arteriosus with resulting systemic arterial hypoxemia. These patients are frequently treated with inhaled nitric oxide (NO) and may require extracorporeal membrane oxygenation; those with severe respiratory failure are at increased risk for neurodevelopmental impairment $(1,2)$. NO's clinical

Received August 23, 2004; accepted January 26, 2005.

Correspondence: Jonathan S. Stamler, M.D., Howard Hughes Medical Institute, Medical Sciences Research Building, Room 321 (Box 2612), Duke University Medical Center, Durham, NC 27710; e-mail: Stam1001@mc.duke.edu.

This work was supported by a Duke Translational Medicine Award.

DOI: 10.1203/01.PDR.0000179399.64025.37 effectiveness has been well documented (3-6), although some reports suggest that it may exacerbate lung inflammation (7), raising the concern that it may have toxic properties in some clinical settings. Infants who receive inhaled NO for PPHN are often treated with high inspired oxygen, and in the $\mathrm{O}_{2}$-rich environment of the lung, higher oxides of nitrogen $\left(\mathrm{NO}_{\mathrm{x}}\right)$ including peroxynitrite may form (8), which can cause hemorrhage, inflammation, and edema $(9,10)$. Airways of animal and human subjects who have received inhaled NO showed the same patterns of oxidative injury found in animals and humans who were exposed to $\mathrm{NO}_{\mathrm{x}}$ or hyperoxia $(11,12)$.

Inhaled, exogenous NO is delivered to well-ventilated parts of the lung and will stimulate guanylate cyclase activity, leading to vascular smooth muscle relaxation. Thus, NO has been effective in lowering pulmonary artery pressure (PAP) 
and PVR without compromising left ventricular function or systemic arterial pressure. As a result, it has been effective in preventing progression to severe PPHN (3), reducing ventilatory support (3), and lessening the need for extracorporeal membrane oxygenation (5). However, in addition to questions about its toxicity, its clinical use has potential drawbacks, which may include methemoglobinemia (13), impairment of left ventricular function (14), impairment of platelet aggregation (15), and "rebound" pulmonary hypertension (16). NO is frequently difficult to administer, and the cost of its use may be staggering (17).

We previously tested a novel inhaled drug, ethyl nitrite (ENO; O-nitrosoethanol), which mimicked NO synthase activity by forming S-nitrosothiols (SNOs) in vitro (18). This drug was effective in mitigating hypoxia-induced pulmonary hypertension and showed promise in improving oxygenation in pulmonary hypertensive neonates (19). ENO did cause, however, modest increases in methemoglobin concentration and a rise in blood ethanol level (in a single infant with liver injury). To better understand the structure-function relationship of this class of compounds, we synthesized a closely related derivative, ethyl nitrate $\left(\mathrm{ENO}_{2} ; \mathrm{O}\right.$-nitroethanol). We hypothesized that as a volatile organic nitrate, it might have an advantage over other vasodilators in that it could be converted easily into an inhaled form and thus selectively dilate the pulmonary vascular bed; in addition, although it would not fortify the body's SNO reservoir as markedly as ENO, its action might be enhanced by thiols such as glutathione, which may be depleted in lung injury (20). We tested our synthetic compound in a vascular bioassay in vitro and in a hypoxic model of PPHN.

\section{METHODS}

Preparation of ethyl nitrate. $\mathrm{ENO}_{2}$ was prepared by sulfuric acid-induced nitration of ethanol. Nitric acid $(25 \mathrm{~mL})$ was mixed slowly with sulfuric acid $(25 \mathrm{~mL})$. Urea $(160 \mathrm{mg})$ was added. The solution was cooled in an ice water bath. Ethanol $(15 \mathrm{~mL})$ was added dropwise in portions over a period of $1 \mathrm{~h}$. After complete addition, the solution was stirred for $10 \mathrm{~min}$ more. The mixture was added to a solution of cold $\left(4^{\circ} \mathrm{C}\right)$ brine in a separation funnel. The bottom (aqueous) layer was discarded, and the top layer was washed twice with cold, saturated sodium bicarbonate $(15 \mathrm{~mL})$, resulting in the evolution of gas. The top layer was washed with cold brine $(15 \mathrm{~mL})$, dried with powdered magnesium sulfate, and filtered to give $\mathrm{ENO}_{2}$ as a clear, colorless liquid.

The ${ }^{1} \mathrm{H}$ nuclear magnetic resonance (NMR) spectrum showed a single organic product with no residual ethanol or other impurities. Observed ${ }^{1} \mathrm{H}$ NMR peaks $\left(\mathrm{CDCl}_{3}\right)$ were as follows: $1.38 \mathrm{ppm}, 3 \mathrm{H}$, triplet; $4.52 \mathrm{ppm}, 2 \mathrm{H}$, quartet. Literature ${ }^{1} \mathrm{H}$ NMR values (21) were as follows: $1.40 \mathrm{ppm}, 3 \mathrm{H}$, triplet; $4.52 \mathrm{ppm}, 2 \mathrm{H}$, quartet. Infrared (IR) nitrate peak was observed at $1664 \mathrm{~cm}^{-1}$. Gas chromatography-mas spectrometry analysis (J\&W Scientific GS-Q column, Folson, $\mathrm{CA}$ ) of the head space of a vial of prepared $\mathrm{ENO}_{2}$ showed the compound to be free of higher $\mathrm{NO}_{\mathrm{x}}$ : two peaks were observed, one of room air, the other with a mass spectrum consistent with $\mathrm{ENO}_{2} . \mathrm{ENO}_{2}$ did not measurably decompose on exposure to air, water, propylene glycol, DMSO, methanol, or ethanol.

An $\mathrm{ENO}_{2}$ gas admixture was generated by passing either 14 or $21 \%$ oxygen, at $0.6 \mathrm{~L} / \mathrm{min}$, through a small glass mixing column (URG, Chapel Hill, NC) filled with rasching rings and containing liquid $\mathrm{ENO}_{2}$ in a propylene glycol solution. Concentrations of $\mathrm{ENO}_{2}$ delivered by this system were changed by varying solution concentrations $(0.0025,0.025,0.125,1.25$, and $2.5 \%)$. Experiments done with "control" gas used propylene glycol in the mixing column, without the addition of $\mathrm{ENO}_{2}$.

Pulmonary artery ring preparation. The ring procurement protocol was approved by the Duke University animal care and use committee. New Zealand White rabbits $(2.5-3 \mathrm{~kg})$ were killed by carbon dioxide inhalation. As vessels would be chemically constricted to mimic hypoxic constriction, vessels from mature rabbits were deemed sufficient. The pulmonary artery was removed and cleared of fat and connective tissue, and second- and third-order branches were cut into 3-mm rings. The rings were prepared and hung as previously described (22). A total of eight pulmonary artery rings from two rabbits were used. Contractions were initiated with phenylephrine, and endothelial function was assessed by the response to $10^{-7} \mathrm{~mol} / \mathrm{L}$ acetylcholine; relaxation of $>50 \%$ was considered adequate. Liquid $\mathrm{ENO}_{2}$ was added to the baths at an initial concentration of $10^{-9} \mathrm{~mol} / \mathrm{L}$ and then increased 10 -fold at a time to a final concentration of $10^{-4} \mathrm{~mol} / \mathrm{L}$. Glutathione $(\mathrm{GSH})$ was tested at up to $10^{-3}$ $\mathrm{mol} / \mathrm{L}$ final concentration.

Surgical model of pulmonary hypertension. The protocol was approved by the Duke University animal care and use committee. A total of 21 neonatal swine (1-2 wk of age; $2.6-4.0 \mathrm{~kg}$ ) were anesthetized and instrumented as previously described (23). Pressure monitors directly measured the pressure in the main pulmonary artery, right ventricle, and left atrium. A flow probe around the pulmonary artery continuously measured cardiac output (CO). In each of a subgroup of these animals $(n=7)$, the ductus arteriosus was found to be patent by placement of a pressure catheter in the ductus during hypoxia, as well as by postmortem examination. Mechanical ventilation was initiated with a V.I.P. Bird ventilator (SensorMedics, Yorba Linda, CA) in volume control mode. Ketamine $(22 \mathrm{mg} / \mathrm{kg})$ and acepromazine $(1.1 \mathrm{mg} / \mathrm{kg})$ were given intramuscularly as preanesthetics. Anesthesia was maintained during the study with a continuous infusion of fentanyl $\left(20 \mu \mathrm{g} \cdot \mathrm{kg}^{-1} \cdot \mathrm{h}^{-1}\right)$, abating some of the inherent instability of the open-chest preparation, and intermittent doses of pancuronium $(0.1 \mathrm{mg} / \mathrm{kg})$ were given for neuromuscular blockade. Blood pressure and heart rate were monitored continuously. Before data acquisition, animals were allowed to stabilize for $20 \mathrm{~min}$.

After instrumentation, lowering the fraction of inspired oxygen $\left(\mathrm{FiO}_{2}\right)$ to 0.14 induced pulmonary hypertension. By $7 \mathrm{~min}$, the PAP had plateaued and the other parameters had reached a constant level. At this point, baseline measurements were taken; measurements were retaken after 5 min of breathing $\mathrm{ENO}_{2}$. The inhaled $\mathrm{ENO}_{2}$ then was stopped, and the animals continued on the low $\mathrm{FIO}_{2}$ for an additional $5 \mathrm{~min}$, at which point hemodynamic measurements were obtained and the $\mathrm{FIO}_{2}$ returned to 0.21 . The procedure was repeated three times using different doses of $\mathrm{ENO}_{2}$ in random order. For the experiments involving thiol supplementation, seven of the animals were pretreated with $\mathrm{GSH}(50 \mathrm{mg} / \mathrm{kg}$, by i.v. infusion over $20 \mathrm{~min}$ ) before induction of pulmonary hypertension (hypoxia); the procedure described above then was followed.

Ventilation and gas administration. Mechanical ventilation was used with an initial rate of 35 breaths/min and a tidal volume sufficient to return 7-9 $\mathrm{mL} / \mathrm{kg}$. Positive end expiratory pressure was set at $5 \mathrm{~cm} \mathrm{H}_{2} \mathrm{O}$, and flow was 6 $\mathrm{L} / \mathrm{min}$. $\mathrm{FIO}_{2}$ was 0.21 before the start of all experiments. Blended air from the ventilator flow meter was directed into the glass mixing column at a flow rate of $0.6 \mathrm{~L} / \mathrm{min}$. The gas that came out of the mixing column (containing gaseous ENO2) was added via t-connector to the inspiratory tubing of the ventilator.

Inspired gas $(400 \mu \mathrm{L})$ was sampled by gastight syringe (Hamilton Co., Reno, NV) through a rubber septum on a port $100 \mathrm{~mm}$ proximal to the endotracheal tube. The minute quantities of $\mathrm{ENO}_{2}$ gas to be analyzed were hydrolyzed with potassium hydroxide $(\mathrm{KOH})$ to potassium nitrite $\left(\mathrm{KNO}_{3}\right)$, which were quantified, after vanadium chloride $\left(\mathrm{VCL}_{3}\right)$ reduction to $\mathrm{NO}$, with a commercial NO (NOA) analyzer (Model 280 NO analyzer; Sievers Instruments, Boulder, $\mathrm{CO}$ ), which was configured and run according to the manufacturer's instructions. $\mathrm{ENO}_{2}$ was unexpectedly resistant to base-induced hydrolysis; solutions of authentic $\mathrm{ENO}_{2}$ required $72 \mathrm{~h}$ at $95^{\circ} \mathrm{C}$ in $100 \mathrm{mM}$ $\mathrm{KOH}$ in a 9:1 mixture of propylene glycol:water to yield $100 \%$ nitrate $(\mathrm{KOH}$ concentration was minimized to reduce background nitrate). The gas was injected into a $200-\mu \mathrm{L}$ solution of $100 \mathrm{mM} \mathrm{KOH}$ in 9:1 propylene glycol:water in a $2-m L$ screw-cap vial. The vial was immediately covered with a screw cap that contained an intact PTFE-faced septum and put on a heat block at $95^{\circ} \mathrm{C}$ for at least $72 \mathrm{~h}$. After cooling, aliquots were removed and analyzed for nitrate content by the NOA. Molar quantities of $\mathrm{ENO}_{2}$ were converted to parts per million (ppm) by application of the ideal gas law.

Data collection and analysis. In vivo data were collected via pressure catheters connected to a data acquisition system customized in our laboratory. Least squares means for the different interventional states were calculated using multiple linear regression, and tests of statistical significance were carried out using repeated measures ANOVA followed by paired $t$ tests with Bonferroni correction. All data were expressed as mean \pm SE. In vitro data were analyzed using ANOVA with Tukey-Kramer honestly significant difference (JMP statistical software, Cary, NC). A $p<0.05$ was considered statistically significant. Analyses were performed using SAS statistical software (SAS Institute, Inc., Cary, NC).

\section{RESULTS}

Dose-dependent response to $\mathrm{ENO}_{2}$ in vitro. Pulmonary artery rings that were exposed to $\mathrm{ENO}_{2}$ showed no vasodilation 
at concentrations below $10^{-7} \mathrm{~mol} / \mathrm{L}$. Dose-dependent relaxation was seen between $10^{-7}$ and $10^{-4} \mathrm{~mol} / \mathrm{L}$ with $\mathrm{IC}_{50}=$ $10^{-4.5} \mathrm{~mol} / \mathrm{L}$ (Fig. 1). Addition of GSH $(1 \mathrm{mM})$ resulted in a small increase in $\mathrm{ENO}_{2}$ potency $(p<0.05$ by multivariate analysis). Univariate analysis also showed a significant potentiation of $\mathrm{ENO}_{2}$ relaxations in the presence of $10^{-4} \mathrm{~mol} / \mathrm{L} \mathrm{GSH}$ $(p<0.05)$. An equivalent volume of ethanol, with and without $\mathrm{GSH}$, produced no relaxation.

Induction of pulmonary hypertension. Table 1 shows the effect of lowering the $\mathrm{FIO}_{2}$ to 0.14 for $7 \mathrm{~min}$. This degree of hypoxia resulted in a 59\% rise in PAP and a $49 \%$ increase in PVR $\left(p<0.05\right.$ for both). The arterial $\mathrm{Po}_{2}\left(\mathrm{PaO}_{2}\right)$ decreased by $52 \%(p<0.01)$. The only statistically significant effect on systemic hemodynamics was a drop in mean arterial blood pressure by $16 \%(p<0.05)$, although the characteristic decline in systemic vascular resistance (SVR) and compensatory increase in $\mathrm{CO}$ was observed. These results are similar to those found in other hypoxic models of pulmonary hypertension $(18,24)$.

Effect of control gas on pulmonary hypertension. To test the effect of delivering air into the inspiratory limb of the ventilatory circuit at $0.6 \mathrm{~L} / \mathrm{min}$, we performed control experiments that consisted of filling the glass chamber with only propylene glycol $\left(0 \% \mathrm{ENO}_{2}\right)$ and then passing gas with an $\mathrm{FIO}_{2}$ of 0.14 through it. In this set-up, the inspiratory and expiratory tidal volumes increased by $5-8 \%$, but the minute ventilation increased by no more than $4 \%$. None of changes in measured parameters reached statistical significance $(p<0.05$, data not shown).

Effect of $\mathrm{ENO}_{2}$ on pulmonary hypertension. Figure 2 shows the changes in several physiologic parameters after $\mathrm{ENO}_{2}$ administration during hypoxia. There was both a significant decrease in PAP and an increase in $\mathrm{PaO}_{2}$ at doses of 0.125 , 1.25 , and $2.5 \% \mathrm{ENO}_{2}(p<0.05)$, with the last two doses also achieving significance versus the control gas. The two lowest doses, 0.0025 and $0.025 \%$, had changes that were similar in magnitude and were not significantly improved versus control
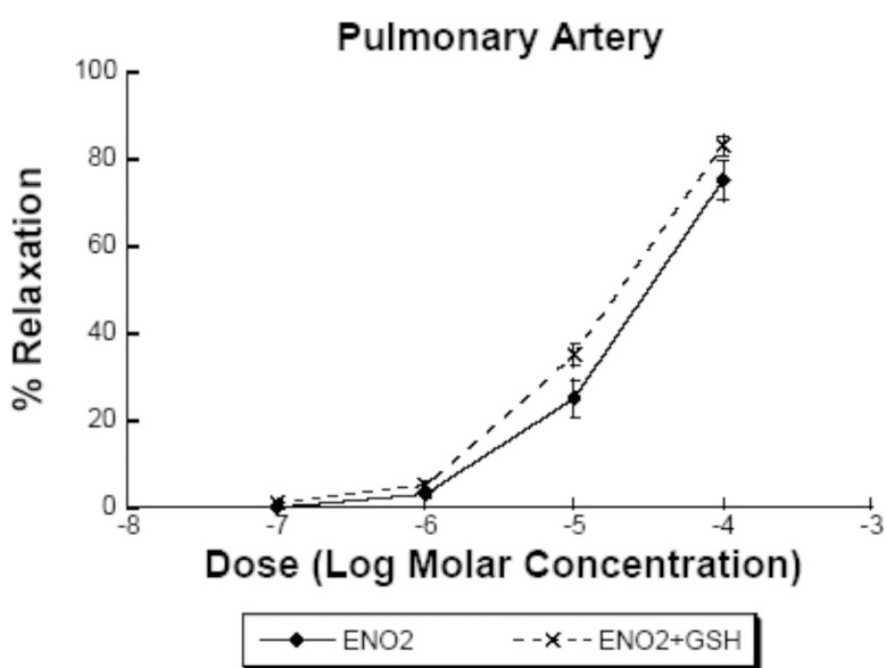

Figure 1. Dose-response curves in isolated pulmonary artery rings. In pulmonary artery rings that were preconstricted with phenylephrine, $\mathrm{ENO}_{2}$ produces relaxation in a dose-dependent manner. The potency of $\mathrm{ENO}_{2}$ is increased by GSH $(p<0.05, n=8)$. Data shown are \pm SEM.
Table 1. Induction of pulmonary hypertension $\left(14 \% \mathrm{O}_{2}\right)$

\begin{tabular}{lcc}
\hline & Normoxia & Hypoxia \\
\hline $\mathrm{PAP}, \mathrm{mm} \mathrm{Hg}$ & $13.9(1.2)$ & $22.1(1.4)^{*}$ \\
$\mathrm{PaO}_{2}, \mathrm{~mm} \mathrm{Hg}$ & $87.0(4.2)$ & $41.7(2.1)^{*}$ \\
$\mathrm{PVR}$, dynes $/ \mathrm{s} / \mathrm{cm}^{-5}$ & $2,947.1(337.8)$ & $4,384.5(501.3)^{*}$ \\
$\mathrm{MnBP}, \mathrm{mm} \mathrm{Hg}$ & $54.0(2.7)$ & $45.3(2.9)^{*}$ \\
$\mathrm{SVR}$, dynes $/ \mathrm{s} / \mathrm{cm}^{-5}$ & $11,741.63(1332.3)$ & $9,106.2(111.1)$ \\
$\mathrm{CO}, \mathrm{mL} / \mathrm{min}$ & $417.2(36.0)$ & $448.4(36.2)$
\end{tabular}

Values are shown as mean (SEM).

$* p<0.05$.
A

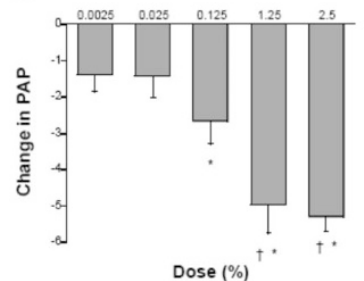

c

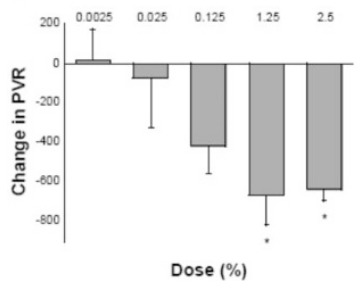

E

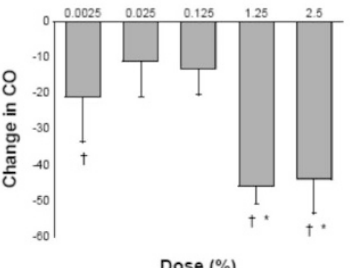

Dose (\%)

G

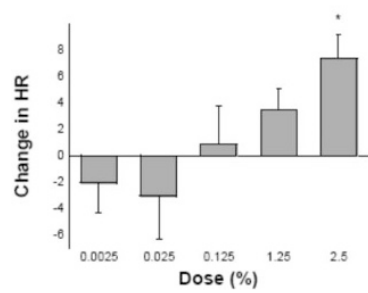

B

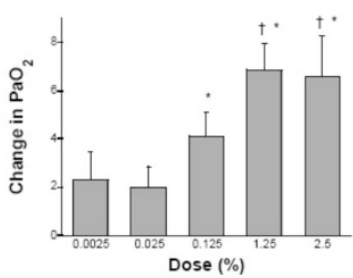

D
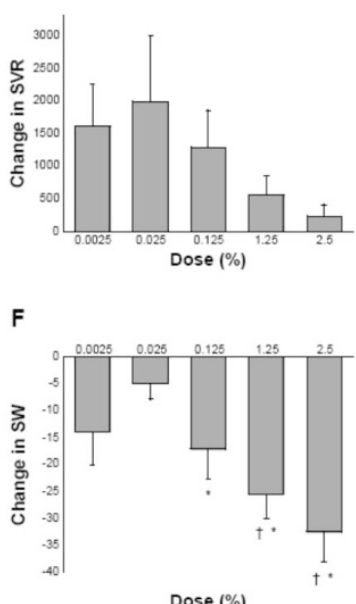

Dose $(\%)$

H

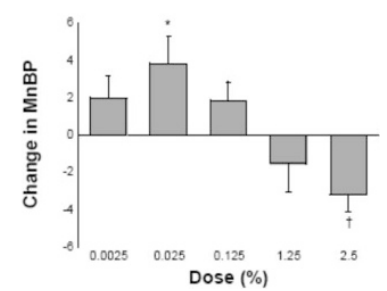

Figure 2. Effects of $\mathrm{ENO}_{2}$ on physiologic parameters in hypoxic model of pulmonary hypertension. The graphs represent the change from hypoxic values after $\mathrm{ENO}_{2}$ had been administered for $5 \mathrm{~min}(n=7$ for each dose). (A) PAP, mmHg. (B) $\mathrm{PaO}_{2}$, mmHg. (C) PVR, dynes $\cdot \mathrm{s}^{-1} \cdot \mathrm{cm}^{-5}$. (D) SVR, dynes $\cdot \mathrm{s}^{-1}$ . $\mathrm{cm}^{-5}$. (E) CO, $\mathrm{mL} / \mathrm{min}$. (F) Right ventricular stroke work, erg*10 $0^{-3} \cdot(G)$ Heart rate, $\min ^{-1}$. (H) mean systemic blood pressure, $\mathrm{mm} \mathrm{Hg}$. * Significantly different from hypoxia $(p<0.05)$; † significantly different from the effect of the control dose $(p<0.05)$.

gas alone. PVR showed a response similar to that of PAP $(p<$ $0.05)$. With the systemic parameters, there was no effect on SVR or heart rate. CO decreased after 1.25 and $2.5 \% \mathrm{ENO}_{2}$, both when compared with the hypoxic, pre- $\mathrm{ENO}_{2}$ state and versus control gas. Right-sided stroke work, an indirect measure of the resistance against the right ventricle, decreased with 
the higher doses $(p<0.05$ for $0.125,1.25$, and $2.5 \%)$. [There was also a decrease in stroke work $(p<0.05)$ when compared with the control dose for 1.25 and $\left.2.5 \mathrm{ENO}_{2}\right]$. Mean arterial blood pressure rose slightly in response to the three lower doses of $\mathrm{ENO}_{2}$ and fell slightly during administration of 1.25 and $2.5 \% \mathrm{ENO}_{2}$. It is interesting that only the response to $0.025 \%$ reached significance $(p=0.04)$, whereas the two highest doses showed a trend toward significance $(p=0.06)$.

Rebound effect. We investigated the short-term effect of discontinuing $\mathrm{ENO}_{2}$ infusion on various cardiovascular parameters, by recording for $5 \mathrm{~min}$ (of continued hypoxia) after the experimental period was complete. The post-ENO $\mathrm{Nalue}_{2}$ was statistically equivalent to the pre- $\mathrm{ENO}_{2}$ value in each instance (data not shown).

Potentiation of $\mathrm{ENO}_{2}$ gas in vivo. To further investigate the effects of thiol supplementation on $\mathrm{ENO}_{2}$, we gave glutathione $(50 \mathrm{mg} / \mathrm{kg}$ ) to the animals before the administration of inhaled drug. The effects of adding GSH are shown in Fig. 3. There was a marked potentiation of the decrease in PAP and the rise in $\mathrm{PaO}_{2}$ in response to $\mathrm{ENO}_{2}$ (Fig. $3 A$ and $B$ ); PAP decreased by $>2.5 \mathrm{~mm} \mathrm{Hg}$ at the three lowest doses, whereas $\mathrm{PaO}_{2}$ increased by $4-5 \mathrm{~mm} \mathrm{Hg}$. With regard to $\mathrm{PaO}_{2}$, GSH effectively shifted the dose-effect of $\mathrm{ENO}_{2}$ leftward, producing improvements from 0.0025 to $0.125 \% \mathrm{ENO}_{2}$ over baseline. GSH also potentiated the decrease in PVR at lower doses of $\mathrm{ENO}_{2}$, whereas the effect of $0.125 \% \mathrm{ENO}_{2}$ was unchanged. GSH did not seem to affect mean systemic blood pressure. An analysis of the subgroup of animals that received GSH showed no attenuation of the hypoxic vasoconstriction after GSH administration.

Measurement of methemoglobin. Methemoglobin concentrations were measured after $5 \mathrm{~min}$ of $\mathrm{ENO}_{2}$ exposure (Table 2 ). The average initial methemoglobin level was $0.7 \%$, and there were no significant increases. The average methemoglo-
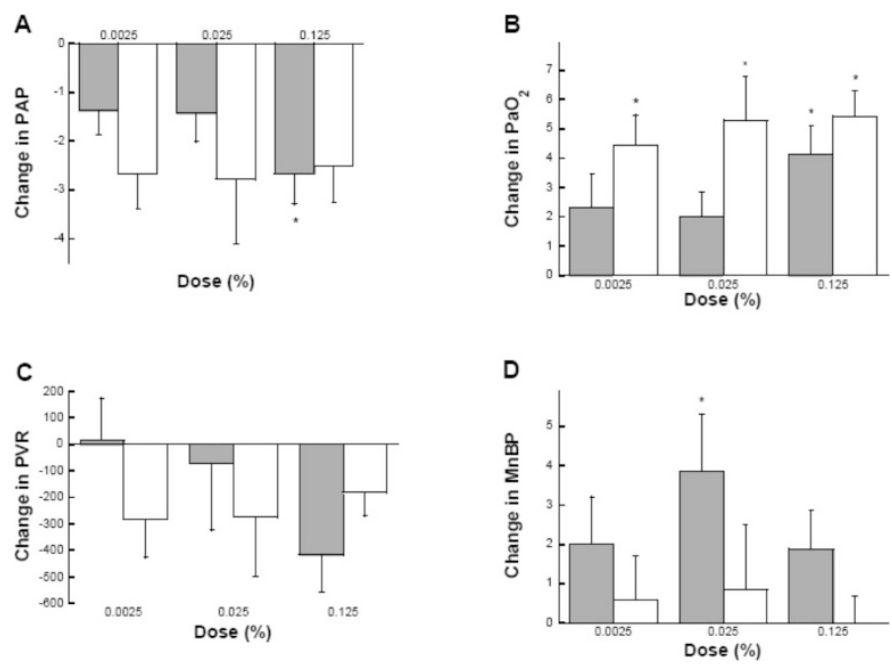

Figure 3. Effect of $\mathrm{ENO}_{2}$ on animals that were pretreated with GSH (50 $\mathrm{mg} / \mathrm{kg}$ ), compared with $\mathrm{ENO}_{2}$ alone. Pulmonary hypertension was induced by lowering the $\mathrm{FIO}_{2}$ to $14 \%$. Shown is the change in $\mathrm{PAP}(A), \mathrm{PaO}_{2}(B), \mathrm{PVR}(C)$, and mean systemic blood pressure $(D)$. Units as in Fig. 2. 圈, change with $\mathrm{ENO}_{2}$ alone; $\square, \mathrm{ENO}_{2}+\mathrm{GSH}$. Mean systemic BP was not significantly affected $(n=7$ for each dose). *Significantly different from hypoxia $(p<$ $0.05)$.
Table 2. Methemoglobin level by concentration

\begin{tabular}{cc}
\hline Concentration & Methemoglobin $(\%)$ \\
\hline Baseline & $0.7(0.04)$ \\
$0.0025 \%$ & $0.6(0.08)$ \\
$0.025 \%$ & $0.6(0.08)$ \\
$0.125 \%$ & $0.6(0.08)$ \\
$1.25 \%$ & $0.8(0.10)$ \\
$2.5 \%$ & $0.8(0.10)$ \\
\hline
\end{tabular}

Values are shown as mean (standard error).

bin after each concentration of $\mathrm{ENO}_{2}$ was within the normal range.

Quantification of $\boldsymbol{E N O}_{2}$ gas. We devised a method of measuring the amount of $\mathrm{ENO}_{2}$ in gas phase by obtaining samples of the gas just proximal to the endotracheal tube and then analyzing it for nitrate content. Liquid concentrations of 1.25 and $2.5 \%$ gave 2000 and 4000 ppm, respectively (Fig. $4)$.

\section{DISCUSSION}

Inhaled NO has been shown to reduce pulmonary pressures and improve oxygenation indices $(6,25,26)$ in patients with pulmonary hypertension, but there is remaining concern about its toxicity in certain populations (27-29) and its use may result in methemoglobinemia (13) and platelet inhibition (30). Inhaled alternatives to $\mathrm{NO}$, including sodium nitroprusside $(31,32)$, nebulized nitroglycerine $(32,33)$, and various NONOates (34) have shown promise but are less well understood from the standpoint of structure-function relationships. We recently showed that the nitrosalcohol gas ENO has activity similar to that of $\mathrm{NO}$ but is resistant to reactions with $\mathrm{O}_{2}$ that generate potentially toxic $\mathrm{NO}_{\mathrm{x}}$. In further contrast with $\mathrm{NO}$, ENO preferentially reacted with cysteine thiols in GSH and hemoglobin to produce SNOs that mediate its effect (18). To better understand the structure-function relationship of these volatile drugs, we synthesized the nitrosalcohol $\mathrm{ENO}_{2}$. That is, we effectively oxidized the $\mathrm{NO}$ moiety in ENO to an $\mathrm{NO}_{2}$ group. We report that this modification attenuates the potency of the drug. We also report, however, that the potency was restored by the addition of a thiol. Thus, we have synthesized

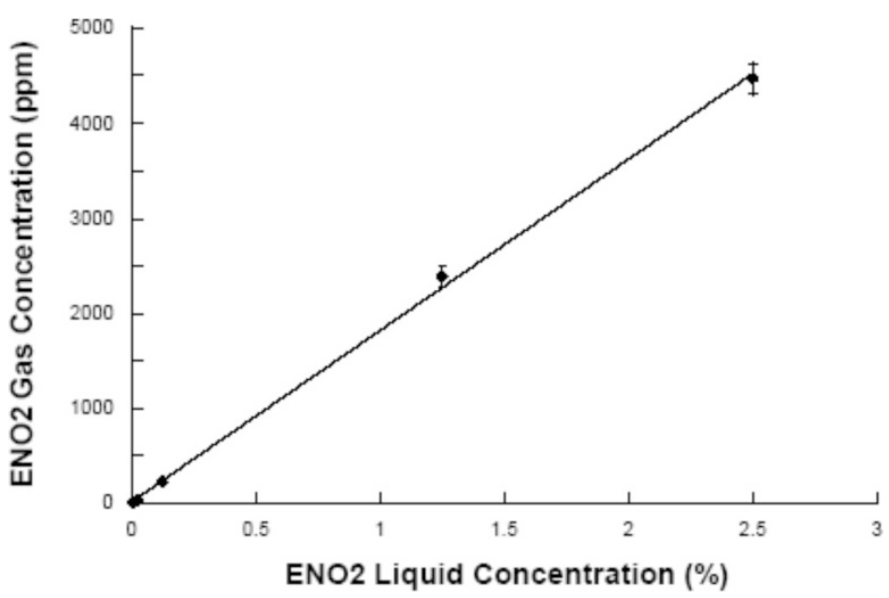

Figure 4. Measured dose of $\mathrm{ENO}_{2}$ in gas phase as related to concentration in liquid phase. 
a novel compound in our laboratory that selectively lowers PAP and raises $\mathrm{Po}_{2}$ while also suppressing the tendency to produce methemoglobin and toxic $\mathrm{NO}_{\mathrm{x}}\left(\mathrm{NO} / \mathrm{O}_{2}\right.$ byproducts). $\mathrm{ENO}_{2}$ 's activity is further regulatable by thiols.

We based our experimental protocol on our previous experience with ENO (18), a potent vasodilator gas that is synthesized in ethanol. There are, however, some notable differences between $\mathrm{ENO}$ and $\mathrm{ENO}_{2}$. Although volatile, $\mathrm{ENO}_{2}$ is a liquid (it has a boiling point of $87.2^{\circ} \mathrm{C}$ ). We synthesized $\mathrm{ENO}_{2}$ using propylene glycol-an odorless, colorless, slightly viscous liquid that boils at $189^{\circ} \mathrm{C}$ - as a solvent. Propylene glycol has been "generally recognized as safe" by the U.S. Food and Drug Administration. Although heavy occupational exposure can lead to upper airway irritation (35), it has been recommended as an appropriate vehicle for routine administration of bronchodilator drugs $(36,37)$. It was not anticipated that our procedure, performed at room temperature, would lead to significant exposure to inhaled propylene glycol.

We compared the in vitro activities of $\mathrm{ENO}$ and $\mathrm{ENO}_{2}$ in organ chamber bioassays. Although both have vasodilatory properties, $\mathrm{ENO}_{2}$ was almost 100 -fold less potent. The potency of $\mathrm{ENO}_{2}$ in vivo was also 100 times less than that of $\mathrm{NO}$ and ENO. Notably, however, with the addition of GSH, the activity of $\mathrm{ENO}_{2}$ in vivo mirrored that of ENO. Specifically, we found marked potentiation by GSH of the effects of $\mathrm{ENO}_{2}$ on PAP, PVR, and $\mathrm{PaO}_{2}$ (Fig. 2). In addition, inhaled $\mathrm{ENO}_{2}$ caused a dose-dependent decrease in right-sided stroke work $(p<0.01)$ and improved oxygenation, which suggests that the decrease in PVR led to improved V/Q matching. A fall in $\mathrm{CO}$ in these experiments is mainly attributable to a reversal of the rise in $\mathrm{CO}$ that accompanied induction of hypoxia. Systemically, there are minimal alterations, with a dose of $2.5 \%$ causing a drop in mean blood pressure comparable to the control gas and no difference in SVR.

The phenomenon of the rebound response is one of the major complications of stopping prolonged inhaled NO therapy $(27,38,39)$. Our protocol allowed for monitoring the response of the animal for an interval of only 5 min after stopping $\mathrm{ENO}_{2}$ inhalation. As the rebound effect was not the major focus of this investigation, we merely noted its absence in this protocol. Similarly, we recognize that our measurement of methemoglobin formation, after only $5 \mathrm{~min}$ of $\mathrm{ENO}_{2}$ exposure, may not be representative of prolonged administration. However, it is important to note that in contrast to what is seen with $\mathrm{NO}$ at relatively high concentrations, the high doses of ENO (2000 ppm) did not cause an increase in methemoglobin.

The biotransformation of organic nitrates involves reactions with sulfhydryl groups (thiols), which may be used in converting $\mathrm{NO}_{2}$ groups to $\mathrm{NO}$ and SNOs. Once in the vascular smooth muscle cell, NO or SNO activates soluble guanylate cyclase to increase intracellular cyclic GMP (40). This in turn leads to a decrease in intracellular calcium and relaxation of vascular smooth muscle. Previous studies have shown a potentiation of nitrate vasodilation by GSH $(41,42)$, which constitutes $>90 \%$ of the intracellular nonprotein thiol pool (40). In our studies, GSH increased the efficacy of $\mathrm{ENO}_{2}$ (as measured by changes in PAP and $\mathrm{PaO}_{2}$ ) at the two lowest doses but not at the higher doses $(0.125 \%$ or higher $)$, concentrations at which the effect of the drug had plateaued. That is, the blood vessels were evidently maximally dilated by the highest doses of $\mathrm{ENO}_{2}$. In effect, pretreating animals with GSH shifted the dose-response curve to the left.

\section{CONCLUSION}

In summary, we have synthesized an organic nitrate that has not been previously studied in mammals. It relaxes constricted pulmonary artery segments in vitro and alleviates pulmonary hypertension and hypoxemia under clinically relevant conditions. Although its effective vaporized concentration is significantly higher than that recommended for NO, it does not seem after short-term administration to produce methemoglobinemia or systemic cardiovascular side effects. In addition, its activity is potentiated by the addition of thiols. This drug merits further studies for optimal dosing and long-term effects, and holds promise as a potential alternative to inhaled NO, particularly in inflammatory settings in which thiol depletion may occur.

Acknowledgments. We gratefully thank Michael Gentile for technical assistance and David Tanaka for help with data analysis.

\section{REFERENCES}

1. Ichiba H, Matsunami S, Itoh F, Ueda T, Ohsasa Y, Yamano T 2003 Three-year follow up of term and near-term infants treated with inhaled nitric oxide. Pediatr Int 45:290-293

2. Walsh-Sukys MC, Bauer RE, Cornell DJ, Friedman HG, Stork EK, Hack M 1994 Severe respiratory failure in neonates: mortality and morbidity rates and neurodevelopmental outcomes. J Pediatr 125:104-110

3. Sadiq HF, Mantych G, Benawra RS, Devaskar UP, Hocker JR 2003 Inhaled nitric oxide in the treatment of moderate persistent pulmonary hypertension of the newborn: a randomized controlled, multicenter trial. J Perinatol 23:98-103

4. Roberts JD Jr, Fineman JR, Morin FC 3rd, Shaul PW, Rimar S, Schreiber MD, Polin RA, Zwass MS, Zayek MM, Gross I, Heymann MA, Zapol WM 1997 Inhaled nitric oxide and persistent pulmonary hypertension of the newborn. The Inhaled Nitric Oxide Study Group. N Engl J Med 336:605-610

5. Finer NN, Barrington KJ 2000 Nitric oxide for respiratory failure in infants born at or near term. Cochrane Database Syst Rev (2):CD000399

6. 1997 Inhaled nitric oxide in full-term and nearly full-term infants with hypoxic respiratory failure. The Neonatal Inhaled Nitric Oxide Study Group. N Engl J Med 336:597-604

7. Chen LW, Hwang YC, Chen CJ, Wang JS, Chen JS, Hsu CM 2003 Burn-induced lung damage in rat is mediated by a nitric oxide/cGMP system. Shock 20:369-74

8. Millar TM 2004 Peroxynitrite formation from the simultaneous reduction of nitrite and oxygen by xanthine oxidase. FEBS Lett 562:129-133

9. Gaston B, Drazen JM, Loscalzo J, Stamler JS 1994 The biology of nitrogen oxides in the airways. Am J Respir Crit Care Med 149:538-551

10. Zhou JL, Jin GH, Yi YL, Zhang JL, Huang XL 2003 Role of nitric oxide and peroxynitrite anion in lung injury induced by intestinal ischemia-reperfusion in rats. World J Gastroenterol 9:1318-1322

11. Lorch SA, Foust R 3rd, Gow A, Arkovitz M, Salzman AL, Szabo C, Vayert B, Geffard M, Ischiropoulos H 2000 Immunohistochemical localization of protein 3-nitrotyrosine and S-nitrosocysteine in a murine model of inhaled nitric oxide therapy. Pediatr Res 47:798-805

12. Lamb NJ, Quinlan GJ, Westerman ST, Gutteridge JM, Evans TW 1999 Nitration of proteins in bronchoalveolar lavage fluid from patients with acute respiratory distress syndrome receiving inhaled nitric oxide. Am J Respir Crit Care Med 160:1031-1034

13. Salguero KL, Cummings JJ 2002 Inhaled nitric oxide and methemoglobin in full-term infants with persistent pulmonary hypertension of the newborn. Pulm Pharmacol Ther $15: 1-5$

14. Loh E, Stamler JS, Hare JM, Loscalzo J, Colucci WS 1994 Cardiovascular effects of inhaled nitric oxide in patients with left ventricular dysfunction. Circulation 90:27802785

15. Gries A, Herr A, Kirsch S, Gunther C, Weber S, Szabo G, Holzmann A, Bottiger BW, Martin E 2003 Inhaled nitric oxide inhibits platelet-leukocyte interactions in patients with acute respiratory distress syndrome. Crit Care Med 31:1697-1704

16. Aranda M, Pearl RG 2000 Inhaled nitric oxide and pulmonary vasoreactivity. J Clin Monit Comput 16:393-401

17. Truog WE, Castor CA, Sheffield MJ 2003 Neonatal nitric oxide use: predictors of response and financial implications. J Perinatol 23:128-132 
18. Moya MP, Gow AJ, McMahon TJ, Toone EJ, Cheifetz IM, Goldberg RN, Stamler JS 2001 S-nitrosothiol repletion by an inhaled gas regulates pulmonary function. Proc Natl Acad Sci USA 98:5792-5797

19. Moya MP, Gow AJ, Califf RM, Goldberg RN, Stamler JS 2002 Inhaled ethyl nitrite gas for persistent pulmonary hypertension of the newborn. Lancet 360:141-143

20. Langley-Evans SC, Phillips GJ, Jackson AA 1996 Sulphur dioxide: a potent glutathione depleting agent. Comp Biochem Physiol C Pharmacol Toxicol Endocrinol 114:89-98

21. Nuclear Magnetic Resonance Spectra. Spectrum 29063M, Vol 49. Sadtler Research Laboratories, Philadelphia

22. Nozik-Grayck E, McMahon TJ, Huang YC, Dieterle CS, Stamler JS, Piantadosi CA 2002 Pulmonary vasoconstriction by serotonin is inhibited by S-nitrosoglutathione. Am J Physiol 282:L1057-L1065

23. Cheifetz IM, Craig DM, Quick G, McGovern JJ, Cannon ML, Ungerleider RM, Smith PK, Meliones JN 1998 Increasing tidal volumes and pulmonary overdistention adversely affect pulmonary vascular mechanics and cardiac output in a pediatric swine model. Crit Care Med 26:710-716

24. Etches PC, Finer NN, Barrington KJ, Graham AJ, Chan WK 1994 Nitric oxide reverses acute hypoxic pulmonary hypertension in the newborn piglet. Pediatr Res 35:15-19

25. Wessel DL, Adatia I, Van Marter LJ, Thompson JE, Kane JW, Stark AR, Kourembanas S 1997 Improved oxygenation in a randomized trial of inhaled nitric oxide for persistent pulmonary hypertension of the newborn. Pediatrics 100:E7

26. Clark RH, Kueser TJ, Walker MW, Southgate WM, Huckaby JL, Perez JA, Roy BJ, Keszler M, Kinsella JP 2000 Low-dose nitric oxide therapy for persistent pulmonary hypertension of the newborn. Clinical Inhaled Nitric Oxide Research Group. N Engl J Med 342:469-474

27. Barnes PJ, Belvisi MG 1993 Nitric oxide and lung disease. Thorax 48:1034-43

28. Gow AJ, Thom SR, Ischiropoulos H 1998 Nitric oxide and peroxynitrite-mediated pulmonary cell death. Am J Physiol 274:L112-L118

29. Horvath EP, doPico GA, Barbee RA, Dickie HA 1978 Nitrogen dioxide-induced pulmonary disease: five new cases and a review of the literature. J Occup Med 20:103-110

30. Beghetti M, Sparling C, Cox PN, Stephens D, Adatia I 2003 Inhaled NO inhibits platelet aggregation and elevates plasma but not intraplatelet cGMP in healthy human volunteers. Am J Physiol 285:H637-H642
31. Schreiber MD, Dixit R, Rudinsky B, Hipps R, Morgan SE, Keith RA, Meadow W 2002 Direct comparison of the effects of nebulized nitroprusside versus inhaled nitric oxide on pulmonary and systemic hemodynamics during hypoxia-induced pulmonary hypertension in piglets. Crit Care Med 30:2560-2565

32. Schutte H, Grimminger F, Otterbein J, Spriestersbach R, Mayer K, Walmrath D, Seeger W 1997 Efficiency of aerosolized nitric oxide donor drugs to achieve sustained pulmonary vasodilation. J Pharmacol Exp Ther 282:985-994

33. Omar HA, Gong F, Sun MY, Einzig S 1999 Nebulized nitroglycerin in children with pulmonary hypertension secondary to congenital heart disease. W V Med J 95:74-75

34. Jacobs BR, Brilli RJ, Ballard ET, Passerini DJ, Smith DJ 1998 Aerosolized soluble nitric oxide donor improves oxygenation and pulmonary hypertension in acute lung injury. Am J Respir Crit Care Med 158:1536-1542

35. Wieslander G, Norback D, Lindgren T 2001 Experimental exposure to propylene glycol mist in aviation emergency training: acute ocular and respiratory effects. Occup Environ Med 58:649-655

36. Cohen BM, Crandall C 1964 Physiologic benefits of "thermo fog" as a bronchodilator vehicle: acute ventilation responses of 93 patients. Am J Med Sci 247:57-61

37. LaKind JS, McKenna EA, Hubner RP, Tardiff RG 1999 A review of the comparative mammalian toxicity of ethylene glycol and propylene glycol. Crit Rev Toxicol 29:331-365

38. McMullan DM, Bekker JM, Johengen MJ, Hendricks-Munoz K, Gerrets R, Black SM, Fineman JR 2001 Inhaled nitric oxide-induced rebound pulmonary hypertension: role for endothelin-1. Am J Physiol 280:H777-H785

39. Chen L, He H, Mondejar EF, Hedenstierna G 2003 Cyclooxygenase inhibitor blocks rebound response after NO inhalation in an endotoxin model. Am J Physiol 284:H290-H298

40. Boesgaard S 1995 Thiol compounds and organic nitrates. Dan Med Bull 42:473-484

41. Lawson DL, Nichols WW, Mehta P, Mehta JL 1991 Captopril-induced reversal of nitroglycerin tolerance: role of sulfhydryl group vs. ACE-inhibitory activity. J Cardiovasc Pharmacol 17:411-418

42. Fung HL, Chong S, Kowaluk E, Hough K, Kakemi M 1988 Mechanisms for the pharmacologic interaction of organic nitrates with thiols. Existence of an extracellular pathway for the reversal of nitrate vascular tolerance by $\mathrm{N}$-acetylcysteine. J Pharmacol Exp Ther 245:524-530 